\title{
BMJ Open Patterns of multiple lifestyle risk factors and their link to mental health in the German adult population: a cross- sectional study
}

\author{
Josefine Atzendorf, ${ }^{1,2}$ Christian Apfelbacher, ${ }^{2}$ Elena Gomes de Matos, \\ Ludwig Kraus, ${ }^{1,3,4}$ Daniela Piontek ${ }^{1}$
}

To cite: Atzendorf J, Apfelbacher C, Gomes de Matos $\mathrm{E}$, et al. Patterns of multiple lifestyle risk factors and their link to mental health in the German adult population: a cross-sectional study. BMJ Open 2018;8:e022184. doi:10.1136/ bmjopen-2018-022184

- Prepublication history for this paper is available online. To view these files, please visit the journal online (http://dx.doi org/10.1136/bmjopen-2018022184).

Received 6 February 2018 Revised 27 August 2018 Accepted 12 October 2018

\section{Check for updates}

(c) Author(s) (or their employer(s)) 2018. Re-use permitted under CC BY-NC. No commercial re-use. See rights and permissions. Published by BMJ.

${ }^{1}$ Department for Epidemiology and Diagnostic, IFT Institut für Therapieforschung, Munich, Germany

${ }^{2}$ Medical Sociology, Institute of Epidemiology and Preventive Medicine, University of Regensburg, Regensburg, Germany

${ }^{3}$ Department of Public Health Sciences, Stockholm University, Stockholm, Sweden

${ }^{4}$ Institute of Psychology, ELTE, Eötvös-Loránd-Universität, Budapest, Hungary

Correspondence to Ms Josefine Atzendorf; Josefine.Atzendorf@klinik.uniregensburg.de

\section{ABSTRACT}

Objectives Lifestyle risk factors, such as drinking or unhealthy diet, can expotentiate detrimental health effects. Therefore, it is important to investigate multiple lifestyle risk factors instead of single ones. The study aims at: (1) identifying patterns of lifestyle risk factors within the adult general population in Germany and (2) examining associations between the extracted patterns and external factors.

Design Cross-sectional study.

Setting General German adult population (aged 18-64 years).

Participants Participants of the 2015 Epidemiological Survey of Substance Abuse ( $n=9204$ ).

Primary outcome measures Lifestyle risk factors (daily smoking, at-risk alcohol consumption, unhealthy diet, low physical activity, weekly use of pharmaceuticals, as well as consumption of cannabis and other illicit drugs).

Results A latent class analysis was applied to identify patterns of lifestyle risk factors, and a multinomial logistic regression was carried out to examine associations between the extracted classes and external factors. A total of four classes were extracted which can be described as healthy lifestyle (58.5\%), drinking lifestyle (24.4\%), smoking lifestyle (15.4\%) and a cumulate risk factors lifestyle (1.7\%). Individuals who were male, at younger age and single as well as individuals with various mental health problems were more likely to show multiple lifestyle risk factors.

Conclusions Healthcare professionals should be aware of correlations between different lifestyle risk factors as well as between lifestyle risk groups and mental health. Health promotion strategies should further focus especially on younger and single men.

\section{INTRODUCTION}

Lifestyle risk factors, like unhealthy diet, low physical activity as well as the consumption of legal and illicit substances are related to the development of several non-communicable diseases, such as cancer and cardiovascular diseases. ${ }^{12}$ In 2012, non-communicable diseases accounted for $68 \%$ ( $\mathrm{n}=38.0$ million) of deaths worldwide. ${ }^{3}$ Therefore, lifestyle risk

\section{Strengths and limitations of this study}

- First study about combined multiple lifestyle risk factors in the general German adult population using national representative data.

- We conducted a latent class analysis including the usage of illicit drugs and pharmaceuticals as lifestyle risk factors, which rarely has been done before.

- We assessed associations between lifestyle risk groups and external factors such as mental health, physical health and sociodemographic factors.

- The study design of the 2015 Epidemiological Survey of Substance Abuse is not able to reach certain subgroups with increased rates of substance consumption, that is, homeless people or inmates.

factors entail significant costs for a society and its economy. Germany's economic costs due to drinking and smoking are estimated at about $€ 26-79$ billion/year, respectively. ${ }^{45}$

Previous literature shows that lifestyle risk factors are associated with each other. ${ }^{67}$ Due to the fact that multiple lifestyle risk factors are more detrimental to health compared with single lifestyle risk factors, ${ }^{89}$ the identification of risk classes might facilitate the development of specific health promotion strategies for different vulnerable population groups. Two German studies examined patterns of health behaviour in a sample of job seekers ${ }^{10}$ and in an older (50 years and above) population. ${ }^{11}$ For example, Schneider and colleagues ${ }^{11}$ identified five different classes: a class with no risk behaviour (25.3\%), a class with drinkers (22.7\%), a physically inactive class $(21.1 \%)$, a class with fruit and vegetable avoiders (18.2\%) and a class with smokers $(12.7 \%)$. In contrast, Schnuerer and colleagues ${ }^{10}$ revealed three classes (substance use, non-exercising overweight, health conscious). 
Neither Schnuerer ${ }^{10}$ nor Schneider ${ }^{11}$ included illicit drugs in their analyses, although associations between cannabis and other substances, like alcohol, tobacco or pharmaceuticals, are often addressed in the scientific literature. ${ }^{12-15}$ In the 2015 German Epidemiological Survey of Substance Abuse (ESA 2015), analgesics were the most commonly used substance after alcohol in Germany. ${ }^{16}$ Furthermore, with a 12 months prevalence of $7.4 \%$, cannabis was the most widely used illicit drug. Given that, it seems both timely and important that these substances are taken into account for the examination of certain patterns of lifestyle risk factors.

Classes with high prevalence rates for lifestyle risk factors are associated with younger age, male gender, lower levels of education, ${ }^{7}$ and mental disorders (eg, major depression).${ }^{17}{ }^{18}$ Additionally, lifestyle risk factors are associated with self-rated health. For instance, a positive state of health seems to be correlated with low to zero consumption of alcohol and tobacco as well as with healthy nutrition and high physical activity. ${ }^{19} 20$

Evidence on the link between multiple lifestyle risk factors, mental disorders, and self-rated health, which is representative of the general population, is currently not available for Germany. The first aim of this study was to assess patterns of multiple lifestyle risk factors (smoking, alcohol consumption, unhealthy diet, low physical activity, consumption of cannabis and other illicit drugs, use of pharmaceuticals) in a nationwide sample in Germany. Second, the study examined if the extracted lifestyle patterns were associated with external factors like sociodemographic factors, self-related health and mental health problems.

\section{METHODS}

\section{Sample and procedure}

The present study is based on data from the ESA 2015. The ESA is a population-representative cross-sectional survey assessing substance use among the general population in Germany ${ }^{21}$ and has been conducted at regular intervals since the 1980s by the IFT Institut für Therapieforschung in Munich, Germany. The adjusted sample comprised 9204 persons aged 18 to 64 years. The sample was drawn by means of a random two-stage selection procedure. At the first stage, 254 sample points (cities, communities) were drawn. Afterwards, the target population was randomly chosen from the sample points' population registers. Paper-and-pencil, telephone and internet-based methods were used to collect the data (net response rate $=52.2 \%$ ). Data were weighted using a redressement weight (age, gender, education, federal states, and district size classes) based on the Iterative Proportional Fitting Algorithm. ${ }^{22}$ The required marginal distributions of the population (18 to 64 years) were taken from the 2014 microcensus. The value of the redressement weight ranges between 0.19 and 5.63 (effectiveness $65.5 \%$ for $\mathrm{n}=5962) .{ }^{21}$ Overall, 5090 women $(49.6 \%)$ and 4114 men $(50.4 \%)$ with an average age of 38.3 years $(\mathrm{SD}=14.7)$ participated in this study.

\section{Participant involvement}

Participants were not involved in the development of the study design or outcome measures. Participation was voluntary and could be terminated at any time. All data were used strictly confidentially and anonymously.

\section{Variables for latent class analysis (lifestyle risk factors)}

To assess patterns of multiple lifestyle risk factors, eight variables were selected: smoking, alcohol consumption, episodic heavy drinking (EHD), diet, physical activity as well as the consumption of cannabis, other illicit drugs and pharmaceuticals (analgesics, hypnotics or tranquillisers). All variables were dichotomised $(0 / 1)$ and assessed whether respondents showed lifestyle risk factors (coded ' 1 ') or favourable lifestyle behaviours (coded ' 0 ').

Risky tobacco consumption was defined as daily smoking of at least one cigarette, cigar, pipe or cigarillo within the last 30 days. Alcohol consumption was measured using a Quantity-Frequency index. The daily consumption of $12 \mathrm{~g}$ (women) or $24 \mathrm{~g}$ (men) of pure alcohol within the last 30 days was characterised as risky alcohol consumption. EHD was defined as consumption of five or more drinks of alcohol consumed on a single day for at least one time within the last 30 days. The consumption of cannabis and other illicit drugs (amphetamines, ecstasy, LSD, heroin and other opioids, cocaine, crack, hallocinogenic mushrooms) as well as the weekly consumption of non-prescribed analgesics, hypnotics or tranquillisers within the last 30 days were defined as lifestyle risk factors. Analgesics included opioid as well as non-opioid drugs.

The rationale for lifestyle risk factors considering physical activity and nutrition was based on guidelines. ${ }^{23}$ For assessing physical activity, participants were asked on how many days per week they had been breathless and sweated because of physical activity within the last 3 months. Participants who were physically active for at least 1 day per week were asked about the average duration of physical activity. The question could be answered on an ordinal scale ( 1 'Less than $10 \mathrm{~min}$ ', 2 ' 10 to less than $30 \mathrm{~min}$ ', 3 '30 to $60 \mathrm{~min}$ ', 4 'More than 60 min'). Based on the questions about frequency and duration of physical activity, a dichotomous variable was generated approximately fulfilling the recommendations of the American College of Sports Medicine and the American Heart Association. ${ }^{24}$ Thus, physical activity for less than 30 min per day on 5 days per week was classified as lifestyle risk factor. Diet was assessed using a validated food frequency questionnaire (LML-6) of six items, asking how often somebody would eat low fat milk products, crudités, fresh salads, fresh herbs, fresh fruits and cereal products. The response categories ranged from 1 (rarely or never) to 5 (several times a day). A nutrition index was calculated ${ }^{23}$ with a low index score $(<10)$ corresponding to an unhealthy diet, indicating a lifestyle risk factor. 


\section{Selected variables for associations with extracted classes (predictors)}

The following variables were selected to examine the association of the healthy lifestyle classes with external factors: sociodemographic factors, self-rated physical health (1, very good to 5 , very bad), self-rated mental health ( 1 , very good to 5, very bad), neurological diseases (no/yes) and a broad range of mental health problems within the last 12 months (ie, depression).

To screen for mental health problems in the past 12 months, screening questions of the following sections of the Munich Composite Diagnostic International Interview (M-CIDI) ${ }^{25}$ were used: panic attacks, general anxiety, social phobia, anxiety of public places, specific phobia, depression, mania and post-traumatic stress disorder (PTSD). Furthermore, the respondents were asked whether they were in treatment for mental health problems or had been diagnosed with a mental disorder. All variables were dichotomised (no/yes).

Sociodemographic information was assessed by questions on gender (male, female), age (18-64 years), marital status (single, married, divorced, widowed), and education (low, average, high). Education was categorised into three groups according to the International Standard Classification of Education. ${ }^{26}$

\section{Data analysis}

A latent class analysis (LCA) was performed on eight categorical lifestyle risk factors as described above. The LCA is a probabilistic model which identifies mutually exclusive classes (risk groups) of a non-directly measurable variable. The LCA calculates the probability that a particular person belongs to a certain (latent) class as well as the probability that an individual in a certain class will give a particular answer. ${ }^{27}$ These probabilities are known as unconditional class membership probability and class-specific response probability. The exact number of classes of the latent variable is not specified by the LCA. Goodness-of-fit measures (Bayesian information criterion (BIC), entropy, Vuong-Lo-Mendell-Rubin adjusted likelihood ratio test (VLMR)) were used to select the best model. A low BIC, high entropy and a significant VLMR indicate the best class-solution, but the final decision was also based on the researchers' assessment of the interpretability of the results. ${ }^{28}$ We tested models with up to five classes. Since the sample of the ESA 2015 was drawn by a two-stage selection procedure, individuals were only selected at random within each sample point. The complex sampling of the ESA data required using a complex mixture term, since the results would be biased otherwise. Furthermore, all data were weighted in order to provide results which are representative for the general adult population in Germany. The LCA was performed in MPlus using maximum likelihood estimation with robust SEs. ${ }^{29}$

The conditional class membership probabilities were further used for a multinomial logistic regression ${ }^{30}$ testing for associations of the classes with external factors
Table 1 Raw and weighted prevalence rates for lifestyle risk factors $(n=9204)$

\begin{tabular}{|c|c|c|c|c|}
\hline \multirow[b]{2}{*}{ Risk factors } & \multirow[b]{2}{*}{$\mathbf{n}$} & \multirow{2}{*}{$\begin{array}{l}\text { Raw } \\
\text { percentages } \\
\% \\
\end{array}$} & \multicolumn{2}{|c|}{$\begin{array}{l}\text { Weighted } \\
\text { percentages }\end{array}$} \\
\hline & & & $\%$ & $95 \% \mathrm{Cl}$ \\
\hline Daily smoking & 1322 & 14.5 & 18.5 & 17.3 to 19.8 \\
\hline At-risk drinking & 1416 & 15.9 & 15.3 & 14.4 to 16.3 \\
\hline $\begin{array}{l}\text { Episodic heavy } \\
\text { drinking }\end{array}$ & 2513 & 27.5 & 25.3 & 24.0 to 26.7 \\
\hline Cannabis use & 386 & 4.2 & 3.1 & 2.7 to 3.6 \\
\hline $\begin{array}{l}\text { Other illicit drugs } \\
\text { use }\end{array}$ & 75 & 0.8 & 0.8 & 0.6 to 1.1 \\
\hline $\begin{array}{l}\text { Weekly } \\
\text { pharmaceuticals } \\
\text { use }\end{array}$ & 733 & 8.0 & 8.2 & 7.5 to 8.9 \\
\hline Unhealthy diet & 6185 & 67.4 & 69.9 & 68.8 to 71.0 \\
\hline $\begin{array}{l}\text { Low physical } \\
\text { activity }\end{array}$ & 6423 & 84.1 & 82.6 & 81.5 to 83.7 \\
\hline
\end{tabular}

n, observed frequency of lifestyle risk factors; \%, prevalence rates; weighted percentages: weighted for age, region, gender and education.

(eg, sociodemographic factors, mental health problems) as described above (listwise deletion of missing data). Classes were used as outcome variables and all predictors were included at once. Control variables were region, citizenship and mode of interview (paper-and-pencil, telephone, internet based). The class with individuals showing the healthiest lifestyle was used as reference category. Risk ratios as well as $95 \%$ CIs were calculated while using sampling weights. There was no sign of multicollinearity among the independent variables. The regression model was run in STATA 12.1 SE. ${ }^{31}$

\section{RESULTS}

\section{Respondent characteristics}

Table 1 presents raw and weighted prevalence rates for lifestyle risk factors. Low physical activity $(82.6 \%)$ and unhealthy diet $(69.9 \%)$ were the two most prevalent lifestyle risk factors. The lowest prevalence rates were reported for the use of cannabis $(3.1 \%)$ and the use of other illicit drugs $(0.8 \%)$. About one quarter of the respondents reported EHD and one-fifth reported daily smoking.

\section{LCA and class profiles}

Latent class models with one to five classes were estimated. Although the entropy indicated a 3-class solution, the 4-class solution was selected as the final model due to better values of BIC, VLMR and the estimated class-specific response probabilities (>0.8) (table 2). Residual-based goodness-of-fit (standardised z-scores) showed only minor violations $(>1.96)$ of the assumption of local independence in all classes (data not shown) and therefore did not affect the selection of the final model. 
Table 2 Goodness-of-fit measures and estimated class-specific response probabilities of the five investigated models for deciding the number of classes $(n=9204)$

\begin{tabular}{|c|c|c|c|c|c|c|c|c|}
\hline \multirow{2}{*}{$\begin{array}{l}\text { Number of } \\
\text { classes }\end{array}$} & \multicolumn{3}{|c|}{ Goodness-of-fit measures } & \multicolumn{5}{|c|}{ Estimated class-specific response probabilities } \\
\hline & Entropy & BIC & VLMR & Class 1 & Class 2 & Class 3 & Class 4 & Class 5 \\
\hline 1 & - & 53267 & - & 1.000 & & & & \\
\hline 2 & 0.634 & 51685 & $\mathrm{p}<0.001^{*}$ & 0.855 & 0.895 & & & \\
\hline 3 & 0.737 & 51556 & $\mathrm{p}=0.018^{\star}$ & 0.814 & 0.780 & 0.935 & & \\
\hline 4 & 0.723 & 51513 & $\mathrm{p}=0.007^{*}$ & 0.884 & 0.833 & 0.910 & 0.803 & \\
\hline 5 & 0.734 & 51535 & $\mathrm{p}=0.384$ & 0.889 & 0.904 & 0.778 & 0.841 & 0.860 \\
\hline
\end{tabular}

${ }^{*} \mathrm{p}<0.05$.

BIC, Bayesian information criterion; VLMR, Vuong-Lo-Mendell-Rubin adjusted likelihood ratio test.

Figure 1 presents the estimated class-specific response probabilities, which are showing the patterns of multiple lifestyle risk factors among the four classes.

Class $1(58.5 \%)$ was characterised by individuals with near-zero probabilities for most of the lifestyle risk factors, except low physical activity and unhealthy diet. In comparison to the other classes, class 1 can be characterised as the healthy lifestyle class.

Class 2 accounted for one-fourth of the sample (24.4\%) and included individuals with high probabilities for risky alcohol consumption, EHD, low physical activity and unhealthy diet as well as moderate probabilities of daily smoking. Class 2 can be described as showing a risky drinking lifestyle. Compared with the healthy lifestyle class, individuals in class 2 were more likely to be younger, male and single as well as having an average education and a German citizenship (table 3). Furthermore, individuals in the drinking lifestyle class were more likely to report symptoms of depression or PTSD (table 4).

Class $3(15.4 \%)$ was characterised by individuals with high probabilities for daily smoking and for showing low physical activity and unhealthy diet. Class 3 was labelled smoking lifestyle class. Compared with the healthy lifestyle class, individuals in class 3 were more likely to be single or divorced as well as having a lower education (table 3). Moreover, the smoking lifestyle class included more individuals who reported symptoms of specific phobia, depression or PTSD as well as bad physical health (table 4).

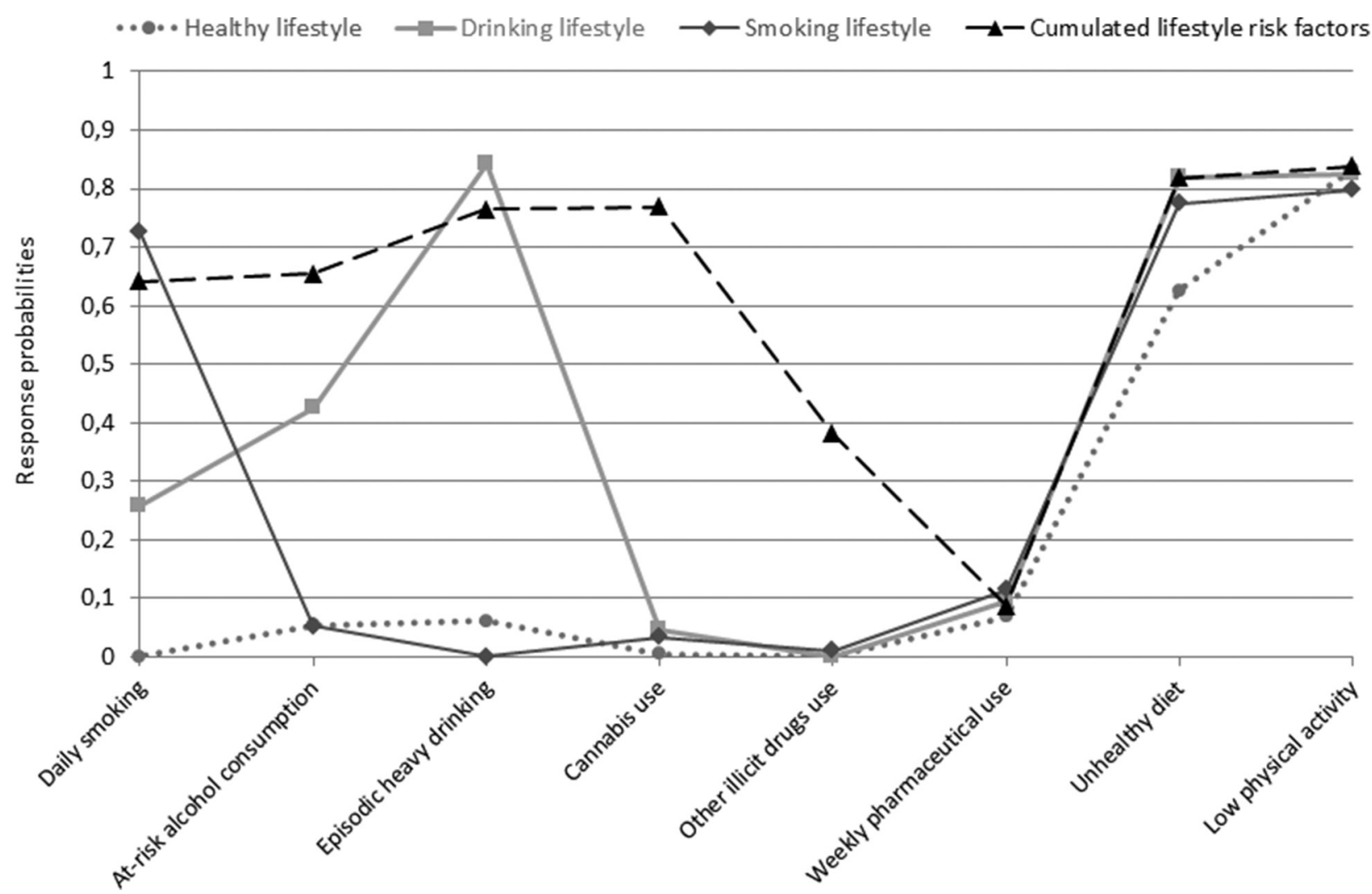

Figure 1 Estimated class-specific response probabilities for eight lifestyle risk factors. Note: A high score indicates a high probability of showing a lifestyle risk factor. 
Table 3 Risk ratios (RRs) and 95\% Cls for sociodemographic factors associated with lifestyle risk factor classes

\begin{tabular}{|c|c|c|c|c|c|c|c|c|}
\hline \multirow{3}{*}{ Variable } & & \multirow{3}{*}{$\begin{array}{l}\text { Class } 1 \\
\text { Healthy } \\
\text { lifestyle } \\
\text { (Reference) }\end{array}$} & \multirow{2}{*}{\multicolumn{2}{|c|}{$\begin{array}{l}\text { Class } 2 \\
\text { Drinking lifestyle }\end{array}$}} & \multirow{2}{*}{\multicolumn{2}{|c|}{$\begin{array}{l}\text { Class } 3 \\
\text { Smoking lifestyle }\end{array}$}} & \multirow{2}{*}{\multicolumn{2}{|c|}{$\begin{array}{l}\text { Class } 4 \\
\text { Cumulate risk factors } \\
\text { lifestyle }\end{array}$}} \\
\hline & & & & & & & & \\
\hline & & & RR & $95 \% \mathrm{Cl}$ & RR & $95 \% \mathrm{Cl}$ & RR & $95 \% \mathrm{Cl}$ \\
\hline \multirow[t]{2}{*}{ Gender } & Male & & 1 & 1 & 1 & 1 & 1 & 1 \\
\hline & Female & & $0.30^{\star * \star}$ & 0.26 to 0.34 & 0.82 & 0.67 to 1.00 & $0.24^{\star \star \star}$ & 0.14 to 0.41 \\
\hline Age & Age & & $0.98^{\star \star \star}$ & 0.97 to 0.98 & 1.01 & 1.00 to 1.01 & $0.94^{\star \star \star}$ & 0.92 to 0.97 \\
\hline \multirow[t]{3}{*}{ Education } & ISCED 1 & & 1 & 1 & 1 & 1 & 1 & 1 \\
\hline & ISCED 2 & & $1.39^{*}$ & 1.10 to 1.75 & 1.01 & 0.71 to 1.42 & 0.72 & 0.37 to 1.38 \\
\hline & ISCED 3 & & 1.15 & 0.89 to 1.49 & $0.47^{\star \star \star}$ & 0.33 to 0.67 & 0.54 & 0.28 to 1.07 \\
\hline \multirow[t]{2}{*}{ Citizenship } & German & & 1 & 1 & 1 & 1 & 1 & 1 \\
\hline & Other & & $0.72^{*}$ & 0.54 to 0.95 & 1.12 & 0.75 to 1.66 & 0.27 & 0.06 to 1.28 \\
\hline \multirow[t]{2}{*}{ Region } & West & & 1 & 1 & 1 & 1 & 1 & 1 \\
\hline & East & & 0.91 & 0.76 to 1.09 & 1.09 & 0.87 to 1.35 & 0.69 & 0.37 to 1.28 \\
\hline \multirow[t]{4}{*}{ Marital status } & Single & & 1 & 1 & 1 & 1 & 1 & 1 \\
\hline & Married & & $0.79^{*}$ & 0.66 to 0.94 & $0.79^{*}$ & 0.62 to 0.99 & $0.24^{\star}$ & 0.09 to 0.62 \\
\hline & Widowed & & $0.23^{*}$ & 0.10 to 0.55 & 0.74 & 0.37 to 1.48 & - & \\
\hline & Divorced & & 1.03 & 0.73 to 1.48 & $1.51^{*}$ & 1.04 to 2.21 & $3.37^{\star}$ & 1.08 to 10.56 \\
\hline
\end{tabular}

The healthy lifestyle class was used as reference category. The results from the regression model are presented in two tables (table 2 and table 3 ) for reasons of clarity and comprehensibility, but only one regression model was calculated.

${ }^{*} \mathrm{p}<0.05,{ }^{* * *} \mathrm{p}<0.001$.

ISCED, International Standard Classification of Education; RR, risk ratio.

The smallest class (1.7\%) showed high probabilities for the use of tobacco, alcohol, cannabis and other illicit drugs as well as for EHD, low physical activity and unhealthy diet. Class 4 can be described as showing a cumulate risk factors lifestyle. Compared with the healthy lifestyle class, individuals in class 4 were more likely to be younger, male, single or divorced (table 3). Additionally, individuals in the cumulate risk factors lifestyle class were more likely to report symptoms of fear of public places (table 4).

\section{DISCUSSION}

\section{Patterns of lifestyle risk factors}

Our study identified four classes of lifestyle risk factors in the German population which can be best described as a healthy lifestyle $(58.5 \%)$, a drinking lifestyle $(24.4 \%)$, a smoking lifestyle $(15.4 \%)$ and a cumulate risk factors lifestyle $(1.7 \%)$.

In a systematic review of multiple lifestyle risk factors, Noble and colleagues ${ }^{7}$ reported that the majority of the respondents $(81 \%)$ in the included studies belonged to a class which did not show any lifestyle risk factors. Furthermore, 33\% of the studies reported a class showing a drinking lifestyle. ${ }^{7}$ In contrast to these studies, we found patterns of lifestyle risk factors which were not reported in previous literature so far. The smallest class was characterised by high probabilities for using all included legal and illicit substances (cumulate risk factors lifestyle). To our knowledge, the consumption of illicit drugs has not been studied before in relation to a class analysis of multiple lifestyle risk factors in a nationally representative sample. Our results suggest including the consumption of illicit drugs in further analyses about multiple lifestyle risk factors in general adulthood and not constraining it to analyses in adolescence. Furthermore, two systematic reviews found a strong association between drinking and smoking. ${ }^{732}$ In the present study, individuals with a high probability for risky alcohol consumption and EHD also had a moderate probability for smoking on a daily basis (class 2). On the other side, individuals with a very high probability for smoking did not have a higher probability for showing risky alcohol consumption (class 3). For further class analyses of multiple lifestyle risk factors, it seems to be an asset to include EHD as well as risky alcohol consumption or alcohol misuse.

Although the results of the present study are consistent with two systematic reviews in some ways, ${ }^{72}$ one should be careful by comparing the results. Previous studies classifying lifestyle risk factors used various definitions, measurements and cut-off points for multiple health behaviour, different statistical methods and diverse samples. ${ }^{732}$ Identification of classes of multiple lifestyle risk factors in the national population on the basis of LCA as the present study has demonstrated have been limited in previous research.

Although the results indicate that more than half of the German population lived a relatively healthy lifestyle regarding consumption of alcohol, tobacco or 
Table 4 Risk ratios (RRs) and 95\% Cls for self-rated physical health, neurological diseases, self-rated mental health and mental health problems associated with lifestyle risk factor classes

\begin{tabular}{|c|c|c|c|c|c|c|c|}
\hline \multirow[b]{3}{*}{ Variable } & \multirow{3}{*}{$\begin{array}{l}\text { Class } 1 \\
\text { Healthy } \\
\text { lifestyle } \\
\text { (Reference) }\end{array}$} & \multirow{2}{*}{\multicolumn{2}{|c|}{$\begin{array}{l}\text { Class } 2 \\
\text { Drinking lifestyle }\end{array}$}} & \multirow{2}{*}{\multicolumn{2}{|c|}{$\begin{array}{l}\text { Class } 3 \\
\text { Smoking lifestyle }\end{array}$}} & \multirow{2}{*}{\multicolumn{2}{|c|}{$\begin{array}{l}\text { Class } 4 \\
\text { Cumulate risk factors } \\
\text { lifestyle }\end{array}$}} \\
\hline & & & & & & & \\
\hline & & $\mathbf{R R}$ & $95 \% \mathrm{Cl}$ & RR & $95 \% \mathrm{Cl}$ & $\mathbf{R R}$ & $95 \% \mathrm{Cl}$ \\
\hline Physical health & & 0.99 & 0.89 to 1.09 & $1.17^{\star}$ & 1.01 to 1.36 & 1.26 & 0.85 to 1.87 \\
\hline Neurological disease & & 0.74 & 0.50 to 1.09 & 0.93 & 0.61 to 1.41 & 1.03 & 0.38 to 2.80 \\
\hline Mental health & & 0.99 & 0.90 to 1.09 & 1.01 & 0.87 to 1.18 & 1.28 & 0.88 to 1.84 \\
\hline \multicolumn{8}{|l|}{ Mental health problems } \\
\hline $\begin{array}{l}\text { Psychosomatic } \\
\text { complaints }\end{array}$ & & 0.91 & 0.73 to 1.13 & 0.97 & 0.73 to 1.29 & 0.94 & 0.43 to 2.03 \\
\hline Panic attacks & & 0.91 & 0.73 to 1.14 & 0.84 & 0.64 to 1.11 & 0.92 & 0.47 to 1.80 \\
\hline $\begin{array}{l}\text { Generalised anxiety } \\
\text { disorder }\end{array}$ & & 1.05 & 0.88 to 1.25 & 0.98 & 0.79 to 1.23 & 1.02 & 0.56 to 1.88 \\
\hline Social phobia & & 0.94 & 0.72 to 1.23 & 0.89 & 0.63 to 1.26 & 1.37 & 0.71 to 2.62 \\
\hline Fear of public places & & 1.01 & 0.62 to 1.63 & 1.26 & 0.74 to 2.14 & $2.86^{*}$ & 1.06 to 7.71 \\
\hline Specific phobia & & 1.00 & 0.77 to 1.31 & $1.36^{\star}$ & 1.02 to 1.81 & 1.33 & 0.59 to 3.00 \\
\hline Depression & & $1.28^{*}$ & 1.09 to 1.51 & $1.56^{\star \star \star}$ & 1.25 to 1.94 & 1.79 & 0.96 to 3.31 \\
\hline Mania & & 1.12 & 0.83 to 1.51 & 1.24 & 0.87 to 1.77 & 1.93 & 0.98 to 3.78 \\
\hline PTSD & & $1.17^{*}$ & 1.01 to 1.35 & $1.44^{*}$ & 1.13 to 1.83 & 1.23 & 0.69 to 2.19 \\
\hline $\begin{array}{l}\text { In treatment/diagnosed } \\
\text { mental disorder }\end{array}$ & & 0.81 & 0.62 to 1.06 & 1.15 & 0.85 to 1.55 & 0.42 & 0.17 to 1.04 \\
\hline
\end{tabular}

The healthy lifestyle class was used as reference category. The results from the regression model are presented in two tables (table 2 and table 3) for reasons of clarity and comprehensibility, but only one regression model was calculated.

${ }^{*} \mathrm{p}<0.05,{ }^{* * *} \mathrm{p}<0.001$

$\mathrm{RR}$, risk ratio.

illicit drugs, even individuals in the healthy lifestyle class showed low physical activity and unhealthy diet. Nonetheless, compared with the other classes, the risk for unhealthy diet was less pronounced for individuals with a healthy lifestyle. Although physical activity and nutrition were not distinctive, the structure of the final class solution preserved when the two variables were not included (sensitivity analyses not shown). In contrast, other German studies found class solutions with differences in regard to physical activity and nutrition. ${ }^{1011} \mathrm{~A}$ possible explanation for this might be that these studies used different definitions of physical activity and nutrition and also used a lower threshold for high physical activity. Schneider and colleagues, ${ }^{11}$ for example, defined physical activity as being active for 1 hour per week within the last year. In addition, the ESA 2015 was only able to assess moderate-intensive physical activity and not vigorous-intensive physical activity, which might have led to an underestimation of physical activity in the sample. As a consequence, the questions for assessing physical activity have been completely revised for future assessments of the ESA. Furthermore, nutrition was assessed with a food frequency questionnaire (LML-6) consisting of six items due to limited space. ${ }^{23}$ Even though the LML-6 was validated, a different questionnaire with more items could have assessed nutrition and unhealthy diet more precisely.

\section{Factors associated with multiple lifestyle risk factors}

Men were more likely to be in the drinking lifestyle $(24.4 \%)$ or cumulate risk factors lifestyle class $(1.7 \%)$ compared to women. This is coherent with the literature, which reports that men have a higher risk of morbidity and mortality because of their higher prevalence of lifestyle risk factors in general. ${ }^{33}$ In the ESA study, men were also more likely than women to consume tobacco, alcohol and cannabis. ${ }^{16}$ It is well known that men also have a higher risk of mortality and morbidity compared to women, but prevention and health promotion strategies are currently more often provided for both genders or especially for women..$^{33}$ In the future, prevention and health promotion strategies should focus especially on men.

Younger people were also more likely to be in the drinking lifestyle or cumulate risk factors lifestyle class. Previous research showed inconsistent associations between age and multiple lifestyle risk factors. Some studies found no clear associations, whereas others also reported that younger individuals were more likely to show multiple lifestyle risk factors. ${ }^{73}$ It seems possible 
that there might be underlying factors which could not be controlled for in this study, but could explain the association between age and lifestyle risk factors, for example, personality traits, household income, peer groups and social networks. ${ }^{35}$ Those underlying factors should be included as moderators or mediators in analyses between age and lifestyle risk factors in the future.

Individuals who were single had a higher risk to show a drinking lifestyle, a smoking lifestyle or cumulate risk factors lifestyle compared with married individuals. Social relationships can have an influence on health behaviour. Especially women tend to show a regulatory role in intimate relationships and support favourable lifestyle behaviours, for example the preparation of a balanced diet. ${ }^{36}$ It should be noted that the term 'single' in the present study also includes individuals who have an intimate relationship but are not married. Nevertheless, it can be expected that the differences between married and single individuals in regard to the lifestyle risk class can be attributed to individuals who are not in an intimate relationship. Drefahl ${ }^{38}$ argued that the socioeconomic status plays an important role in regard to health behaviour and marital status. In his study, cohabiters who were not married and possessed a high socioeconomic status had a lower risk for mortality than married couples. ${ }^{38}$ Further research should investigate how intimate relationships in particular have an influence on lifestyle risk factors and if there might be more underlying factors explaining this association.

Additionally, in the present study people with a German citizenship were more likely to be in the drinking lifestyle class. A study by Strupf and colleagues ${ }^{39}$ also reported differences among people with and without migration background considering alcohol consumption, but further research is needed to assess motives for EHD among various cultural groups.

Furthermore, education was also associated with lifestyle risk groups. Individuals with a lower education were more likely to have a smoking lifestyle, whereas individuals with a moderate education were more likely to have a drinking lifestyle. It is consistent to literature that smoking is associated with lower education ${ }^{40} 41$ and lifestyle risk groups, including alcohol intake, are associated with higher education. ${ }^{742}$ Future research should address the question if the educational level has an effect on the awareness of health-compromising effects regarding at-risk alcohol consumption and smoking.

\section{Associations between lifestyle risk groups and mental health}

The present study also looked at associations between lifestyle risk classes and mental health problems, which has not been done before with a nationally representative sample in Germany. Compared with the healthy lifestyle class, individuals in the cumulate risk factors lifestyle class were more likely to report symptoms of fear of public places. The National Academy of Science recently reported that there is a moderate statistical association between regular cannabis use and increased symptoms of social anxiety. ${ }^{43}$ Also consistent with the scientific literature were the findings that individuals with a drinking lifestyle were likely to report symptoms of depression ${ }^{18}$ and that individuals with a smoking lifestyle were more likely to report symptoms of depression, PTSD or specific phobia. ${ }^{17}$ On the other side, it is also possible that people with mental health problems are more likely to use legal or illicit substances for self-medication. ${ }^{44}$ Since we investigated correlations and not causality, these results should be interpreted with caution.

\section{Limitations}

One shortcoming of this study is that the ESA study design does not reach certain subgroups with increased rates of substance consumption, that is, homeless people or inmates. ${ }^{45}$ A further risk of bias results from the data collection in the form of self-reports which are prone to social desirability bias. ${ }^{21}$ Unfortunately, the ESA 2015 data collection did not distinguish between the usage of non-prescribed opioid and non-opioid pharmaceuticals within the last 30 days. Furthermore, it was not assessed if participants had misused prescribed pharmaceuticals. Since the present study was a cross-sectional analysis, one cannot tell if individuals change between lifestyle risk groups over lifetime. In the future, research with longitudinal studies in regard to this topic is necessary as well as the investigation which factors could lead to a change of health behaviour.

Despite these limitations, the ESA provides a large sample and a good response rate. ${ }^{21}$ Furthermore, based on the use of different modes of administration and weighting procedures, the ESA provides representative estimates for lifestyle risk factors in the general adult population in Germany.

\section{CONCLUSIONS}

The study shows patterns of lifestyle risk factors regarding the use of alcohol, EHD, tobacco, cannabis, other illicit drugs, pharmaceuticals as well as nutrition and physical activity. Some of the associations between lifestyle risk factors are already well documented in the literature, which emphasises the plausibility of the results that were found. However, the study also adds new contributions to the scientific community. Based on the outcomes, we recommend three practical implications for the German population:

1. Young and single men were more likely to have an alcohol or cumulate risk factors lifestyle. In the future, prevention and health promotion strategies should focus especially on men, since they also have a higher risk for morbidity and mortality in general. ${ }^{33}$

2. Individuals with various mental health problems were more likely to show multiple lifestyle risk factors. Prevention and health promotion strategies should address the associations between multiple lifestyle risk factors and mental health problems. Additionally, professionals at the healthcare sector should also look at 
multiple lifestyle risk factors in patients with probable mental health disorders.

3. The high probabilities for unhealthy diet and low physical activity emphasise the importance of the promotion of regular physical activity and healthy nutrition in wide sections of the German population through intervention and prevention measures.

Contributors DP, LK and EGdM designed the study and supervised the process of data collection. JA, EGdM and DP were responsible for data cleaning and creating the final dataset. JA conducted the statistical analysis and wrote the manuscript. DP and CA played a major role for developing the final outline for analysing the data. All authors contributed to and have approved the final manuscript.

Funding The ESA 2015 was supported by the German Federal Ministry of Health (IIA5 -2514DSM200). The article was supported by the German Research Foundation (DFG) within the funding programme Open Access Publishing.

Competing interests LK and DP declare having received a grant from Lundbeck GmbH for a research project on alcohol epidemiology not related to this study.

Patient consent for publication Not required.

Ethics approval The ESA was approved by the ethics committee of the German Psychological Society (DGPs; Reg.-No: GBLK06102008DGPS).

Provenance and peer review Not commissioned; externally peer reviewed.

Data sharing statement For scientific purposes it is possible to use the raw data of the Epidemiological Survey of Substance Abuse. All datasets (since 1980) are archived at GESIS Leibniz Institute for Social Research and can be requested there.

Open access This is an open access article distributed in accordance with the Creative Commons Attribution Non Commercial (CC BY-NC 4.0) license, which permits others to distribute, remix, adapt, build upon this work non-commercially, and license their derivative works on different terms, provided the original work is properly cited, appropriate credit is given, any changes made indicated, and the use is non-commercial. See: http://creativecommons.org/licenses/by-nc/4.0/.

\section{REFERENCES}

1. World Health Organisation,. The world health report 2002 - Reducing Risks, Promoting Healthy Life. Geneva: World Health Organisation, 2002.

2. World Health Organisation. Diet, nutrition and the prevention of chronic diseases. WHO technical report series. Geneva: World Health Organisation, 2003.

3. World Health Organisation,. Global status report on noncommunicable diseases. Geneva: World Health Organisation, 2014.

4. Effertz T, Adams M. Economic cost of the consumption of alcohol and tobacco. [Original title: Volkswirtschaftliche Kosten des Alkoholund Tabakkonsums], in Alcohol and tobacco. In: Mann K, Singer M, Batra A, eds. Fundamentals and secondary diseases. [Original title: Alkohol und Tabak. Grundlagen und Folgeerkrankungen]: Thieme: Stuttgart, 2011:57-62.

5. Effertz T. The economic cost of hazardous consumption. A theoretical and empirical analysis for Germany using the example alcohol, tobacco and obesity: In. [Original title: Die volkswirtschaftlichen Kosten gefährlichen Konsums. Eine theoretische und empirische Analyse für Deutschland am Beispiel Alkohol, Tabak und Adipositas]. Frankfurt am Main: Peter Lang, 2015.

6. de Vries H, van 't Riet J, Spigt M, et al. Clusters of lifestyle behaviors: results from the Dutch SMILE study. Prev Med 2008;46:203-8.

7. Noble N, Paul C, Turon $\mathrm{H}$, et al. Which modifiable health risk behaviours are related? A systematic review of the clustering of Smoking, Nutrition, Alcohol and Physical activity ('SNAP') health risk factors. Prev Med 2015;81:16-41.

8. Khaw KT, Wareham N, Bingham S, et al. Combined impact of health behaviours and mortality in men and women: the EPIC-Norfolk prospective population study. PLoS Med 2008;5:e12.

9. Kvaavik E, Batty GD, Ursin G, et al. Influence of individual and combined health behaviors on total and cause-specific mortality in men and women: the United Kingdom health and lifestyle survey. Arch Intern Med 2010;170:711-8.

10. Schnuerer I, Baumann S, Haberecht K, et al. Patterns of health risk behaviors among job-seekers: a latent class analysis. Int J Public Health 2015;60:111-9.
11. Schneider S, Huy C, Schuessler M, et al. Optimising lifestyle interventions: identification of health behaviour patterns by cluster analysis in a German 50+ survey. Eur J Public Health 2009;19:271-7.

12. Godeau E, et al. Cannabis use by 15 -year-old schoolchildrenData from the WHO international survey in 32 western countries. Alcoologie et Addictologie 2007;29:s28-s34.

13. Primack BA, Kim KH, Shensa A, et al. Tobacco, marijuana, and alcohol use in university students: a cluster analysis. J Am Coll Health 2012;60:374-86.

14. Morley KI, Lynskey MT, Moran P, et al. Polysubstance use, mental health and high-risk behaviours: Results from the 2012 Global Drug Survey. Drug Alcohol Rev 2015;34:427-37.

15. Smith GW, Farrell M, Bunting BP, et al. Patterns of polydrug use in Great Britain: findings from a national household population survey. Drug Alcohol Depend 2011;113(2-3):222-8.

16. Gomes de Matos E, et al. Substance use in the German general population: Results of the 2015 Epidemiological Survey of Substance Abuse. [Original title: Substanzkonsum in der Allgemeinbevölkerung in Deutschland: Ergebnisse des Epidemiologischen Suchtsurveys 2015]. Sucht 2016;62:271-81.

17. Verger $P$, Lions $C$, Ventelou $B$. Is depression associated with health risk-related behaviour clusters in adults? Eur J Public Health 2009;19:618-24.

18. Vermeulen-Smit E, Ten Have M, Van Laar M, et al. Clustering of health risk behaviours and the relationship with mental disorders. $J$ Affect Disord 2015;171:111-9.

19. Conry MC, Morgan K, Curry P, et al. The clustering of health behaviours in Ireland and their relationship with mental health, selfrated health and quality of life. BMC Public Health 2011;11:692.

20. Sargent-Cox K, Cherbuin N, Morris L, et al. The effect of health behavior change on self-rated health across the adult life course: a longitudinal cohort study. Prev Med 2014;58:75-80.

21. Piontek D, et al. The 2015 Epidemiological Survey of Substance Abuse: Study Design and Methodology. [Original title: Der Epidemiologische Suchtsurvey 2015: Studiendesign und Methodik]. Sucht 2016;62:259-69.

22. Gelman A, Carlin J. Poststratification and weighting adjustments, in Survey nonresponse. Groves RM, Little RJA, Eltinge JL, eds. Wiley: New York, 2002:289-203.

23. Keller S. On the validity of the transtheoretical model. A study on the change in dietary behavior [dissertation]: In. [Original title: Zur Validität des Transtheoretischen Modells - Eine Untersuchung zur Veränderung des Ernährungsverhaltens], 1998. http://archiv.ub.unimarburg.de/diss/z1998/0303/html/frame.htm (cited 15 Jun 2018).

24. Haskell WL, Lee IM, Pate RR, et al. Physical activity and public health: updated recommendation for adults from the American College of Sports Medicine and the American Heart Association. Circulation 2007:116:1081-93.

25. Wittchen $\mathrm{H}$, et al. Münchener Composite International Diagnostic Interview (M-CIDI, Paper-Pencil 2.2, 2/95): Munich: Max-PlanckInstitute for Psychiatry, Clinical Institute, 1995.

26. United Nations Educational Scientific and Cultural Classification (UNESCO). International Standard Classification of Education ISCED, 2011. http://uis.unesco.org/sites/default/files/documents/ international-standard-classification-of-education-isced-2011-en pdf. (cited 18 Jun 2018).

27. Gollwitzer M, Latent-Class-Analysis, in Test theory and questionnaire construction [Oiginal title: Testtheorie und Fragebogenkonstruktion]. Kelava A, Moosbrugger H, eds. Springer-Verlag: Berlin/ Heidelberg, 2012.

28. Geiser C. Data analysis with Mplus [Original title: Datenanalyse mit Mplus. Wiesbaden: VS Verlag für Sozialwissenschaften, 2010.

29. Muthén L, Muthén B. Mplus User's Guide. 6th ed. Los Angeles, CA: Muthén \& Muthén, 2010.

30. Berry WD, Feldman S. Multiple regression in practice. Sage university paper series on quantitative applications in the social sciences. Beverly Hills, CA: Sage, 1985.

31. STATA 12.1 SE, (Stata Corp LP; College Station, TX).

32. Meader N, King K, Moe-Byrne T, et al. A systematic review on the clustering and co-occurrence of multiple risk behaviours. BMC Public Health 2016;16:657.

33. Robert Koch-Institut (RKI). Health situation of men in Germany. [Original title: Gesundheitliche Lage der Männer in Deutschland]: In. Beiträge zur Gesundheitsberichterstattung des Bundes. Berlin: RKI, 2014.

34. Cook PA, Bellis MA. Knowing the risk: relationships between risk behaviour and health knowledge. Public Health 2001;115:54-61.

35. Wachter D. Psychological aspects of health behaviour in adolescents. Results of a longitudinal study [diploma thesis]: In. [Original title: Psychologische Aspekte des Gesundheitsverhaltens bei 
Jugendlichen. Resultate einer Längsschnittstudie]. Vienna (Austria): University of Vienna, 2011.

36. Miller E, Wortmann C, Kristenson M, Weiderner G, Kopp MGender differences in morbidity and mortality following a major stressor: the case of conjugal bereavement., in Heart disease: environment, stress, and gender: , eds. IOS Press: Amsterdam, 2002:251-66.

37. Umberson D. Family status and health behaviors: social control as a dimension of social integration. J Health Soc Behav 1987;28:306-19.

38. Drefahl S. Do the married really live longer? The role of cohabitation and socioeconomic status. Journal of Marriage and Family 2012;74:462-75.

39. Strupf $\mathrm{M}$, et al. Trinkverhalten von Personen verschiedener Herkunftsregionen in Deutschland: Ein Vergleich mit Personen ohne Migrationshintergrund. Suchttherapie 2016;18:90-7.

40. Lopez AD, Collishaw NE, Piha T. A descriptive model of the cigarette epidemic in developed countries. Tobacco Control 1994;3:242-7.
41. Schaap MM, Kunst $A E$, Leinsalu $M$, et al. Female ever-smoking, education, emancipation and economic development in 19 European countries. Soc Sci Med 2009;68:1271-8.

42. Rebholz CE, Rueegg CS, Michel G, et al. Clustering of health behaviours in adult survivors of childhood cancer and the general population. Br J Cancer 2012;107:234-42.

43. National Academies of Sciences Engineering and Medicine, The Health Effects of Cannabis and Cannabinoids: The Current State of Evidence and Recommendations for Research: The National Academies Press, 2017.

44. Lobbana F, Barrowclough C, Jeffery S, et al. Understanding factors influencing substance use in people with recent onset psychosis: A qualitative study. Soc Sci Med 2010;70:1141-7.

45. Fazel S, Khosla V, Doll H, et al. The prevalence of mental disorders among the homeless in western countries: systematic review and meta-regression analysis. PLoS Med 2008;5:e225. 